\title{
Advantages and disadvantages of total arterial coronary artery bypass graft as compared to venous coronary artery bypass graft
}

\author{
Dickson Dewantoro ${ }^{1}$, Antonio Nenna², Umberto Satriano ${ }^{2}$, Massimo Chello ${ }^{2}$, Cristiano Spadaccio ${ }^{1}$ \\ 'Department of Cardiothoracic Surgery, Golden Jubilee National Hospital, Glasgow G81 4DY, UK. \\ ${ }^{2}$ Department of Cardiovascular Surgery, Università Campus Bio-Medico di Roma, Rome 00128, Italy.
}

Correspondence to: Dr. Cristiano Spadaccio, Department of Cardiothoracic Surgery, Golden Jubilee National Hospital, Agamemnon St, Glasgow, Clydebank G81 4DY, UK. E-mail: cristianospadaccio@gmail.com

\begin{abstract}
How to cite this article: Dewantoro D, Nenna A, Satriano U, Chello M, Spadaccio C. Advantages and disadvantages of total arterial coronary artery bypass graft as compared to venous coronary artery bypass graft. Vessel P/us 2018;2:20. http://dx.doi. org/10.20517/2574-1209.2018.50
\end{abstract}

Received: 26 Jun 2018 First Decision: 17 Jul 2018 Revised: 23 Jul 2018 Accepted: 26 Jul 2018 Published: 16 Aug 2018

Science Editor: Mario F. L. Gaudino, Cristiano Spadaccio Copy Editor: Jun-Yao Li Production Editor: Huan-Liang Wu

\begin{abstract}
Considering the plethora of literature about surgical revascularization, this review aims to discuss the most recent studies about the effects of total arterial coronary artery bypass graft (TACABG) compared with CABG that involves venous graft (VCABG) in patients with multivessel coronary artery disease. Patients were sampled from published papers that studied various aspects involving TACABG or VCABG. Resulting samples were used to compare the complexity and 5 years' outcomes of TACABG to VCABG in the revascularization of coronary arteries. TACABG provides a better prognosis with average all-cause mortality within 5 years of $5.35 \%$ as compared to VACABG with average of all-cause mortality within 5 years of $9.1 \%$. Furthermore, assumption of deep sternal wound infection from TACABG, especially when bilateral internal thoracic arteries were used, is very technique-dependent, as reports have been showing that the rate of such infection to occur is less than 1\%. TACABG was concluded to wield a better prognosis within both short- and long- terms, although more research need to be done to prove its use in left main disease.
\end{abstract}

Keywords: Total arterial, internal thoracic artery, coronary artery disease, myocardial revascularization, coronary artery bypass graft

\section{INTRODUCTION}

Coronary heart disease, or coronary artery disease (CAD), commonly caused by atherosclerosis, as mentioned by World Health Organization, has markedly lower prevalence within populations with lower life expectancy. However, the presence of risk factors contributes greatly towards the prevalence of CAD, and 3.8

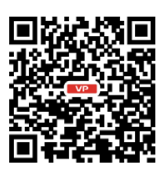


million men and 3.4 million women died of CAD each year ${ }^{[1]}$. Therefore, there is urgent need for prevention, early recognition, and proper management of $\mathrm{CAD}$ in order to reduce mortality while also improving quality of life.

Percutaneous coronary intervention (PCI) provides a way for emergency intervention of CAD in the setting of acute coronary syndromes and provides a less invasive intervention of CAD in stable patients. According to an international, open-label, multicenter randomized trial that compared everolimus-eluting stents with coronary artery bypass graft (CABG) for the management of patients with left main disease, the 3 years' rate of death from any cause, stroke, or myocardial infarction of PCI was higher than the CABG group at $15.4 \%$ and $14.7 \%$ respectively. However, these differences did not seem to be very significant ${ }^{[2]}$.

CABG is part of a routinely done revascularization intervention to manage CAD by using grafted vessels to revascularize vessels distal from the blockage. Various grafts can be obtained from different sources, which include veins (especially saphenous vein) and arteries (such as radial artery and internal mammary arteries). This article is written to discuss the advantages and disadvantages of using each type of grafts based on results provided by existing studies. This article is mainly aimed at comparing total arterial coronary artery bypass graft (TACABG) with CABG that involves venous graft (VCABG) in term of benefits for patients who suffered from CAD from the surgeon's perspective. In common clinical practice, left anterior descending is grafted with an arterial conduit, generally the left internal thoracic artery; other grafts could be performed using arterial of venous conduits, with single grafts, sequential grafts or composite grafts. In TACABG, all grafts are arterial and therefore no veins are used for revascularization, while in VCABG at least one graft derives from a vein. In brief, differences between arterial and venous grafts will be discussed, in terms of harvesting and complications, and then the results of the most significant clinical trials will be summarized.

\section{DIFFERENCES IN HARVESTING BETWEEN VENOUS AND ARTERIAL GRAFTS}

\section{Grafts: complexity pre- operatively and peri-operatively}

Complexity of each graft can be assessed by comparing the requirements for preparations of procedures, time taken to do the surgery, and skills required to perform the surgery. When surgeons decided to choose radial artery as a conduit, they need to make sure that the compensating ulnar artery is working properly, thus, there is a need to do a modified Allen's test. This is not the case for saphenous venous graft, which also has the advantage of being longer and easier to handle ${ }^{[3]}$.

During the operation, the standard procedure, according to a retrospective multicenter study, is for all patients to undergo median sternotomy for the open-heart surgery. Firstly, when internal thoracic arteries (ITAs) (also known as internal mammary arteries, IMAs) are required, they are obtained in a skeletonized or semi-skeletonized manner. Secondly, when radial arteries (RAs) are required, they are supposed to be done through sharp dissection to provide open atraumatic entry and the arterial extraction would then be supplemented by the use of low-power cautery or harmonic scalpel. Lastly, when saphenous vein grafts (SVGs) are required, open entry technique in the lower leg is done while avoiding the thigh vein ${ }^{[4,5]}$.

While trying to find out the average time taken to do each types of CABG, there was no studies that specifically show the total time taken for each procedure. However, operative time can be interpreted as the sum of perfusion time (Cardio-pulmonary Bypass time) and cross clamp time ${ }^{[6]}$. This information is available from a retrospective study about the effectiveness of total arterial revascularization. In the study, the mean crossclamp time for total arterial revascularization and non- total arterial revascularization are 60.6 and $63.8 \mathrm{~min}$ respectively; and the perfusion times for each groups are 80.2 and 90.7 respectively ${ }^{[4]}$. Even though patients are given prophylaxis antibiotics, it is logical that increased open surgery time is equal to increased risk of infection.

\section{Radial artery: between intrinsic limitations and clinical effectiveness}

A few papers have summarized the important limitations of radial artery that need to be taken into consid- 
eration while being chosen as a conduit ${ }^{[7,8]}$. As discussed above, there is a requirement for the adequacy of ulnar flow in order to act as a collateral blood supply. This can be assessed by modified Allen's test and complemented by pulse oximetry and echo-Doppler. Also, calcified radial arteries or those with diameter of less than $2 \mathrm{~mm}$ are generally excluded from harvesting. There might be sensory abnormalities and motor weakness in the forearm after removal of radial arteries, and there is a requirement for the use of vasodilators as radial arteries are infamous for their striking spastic reactions to vasoconstrictors and hypothermia. While skeletonization is described to provide a longer graft with larger diameters, less spasms, and better patency frequencies, it increases the harvesting time and the risk of severe graft injury ${ }^{[8]}$.

However, a recent metanalysis evaluated 534 patients with radial-artery grafts and 502 patients with saphenous-vein grafts, concluding that as compared with the use of saphenous-vein grafts, the use of radial-artery grafts for $\mathrm{CABG}$ resulted in a lower rate of adverse cardiac events and a higher rate of patency at 5 years of follow-up. At follow-up angiography, the use of radial-artery grafts was also associated with a significantly lower risk of occlusion (hazard ratio: 0.44); lower incidence of myocardial infarction (hazard ratio: 0.72) and a half incidence of repeat revascularization ${ }^{[9]}$.

\section{POST-OPERATIVE OUTCOMES}

The post-operative outcome of a procedure is crucial in deciding on whether such procedure is worth doing, especially in term of benefits and harm for the patients. Several studies have compared the outcome of coronary artery revascularization that will be compared in this article (considering only CABG) and comparing the data based on whether CABG done in the study is TACABG or VCABG.

\section{Patency}

In general, when comparing ITA and SV when they were acting as conduits, several studies such as a followup Cooperative Studies Trial done by Goldman et al. ${ }^{[10]}$, showed that ITA had better patency as shown by the 10 -year angiogram of the study mentioned. The 10 -year patency was $61 \%$ for SVG and $85 \%$ for ITA. However, the number of patients has been declining during the 10 years' period, so that at 1 week the study cohort consisted of 1025 patients but at 10 years follow up the study cohort declined to just 85 patients. However, from the study's graft, it is shown that the percentage of patent grafts has always been higher in ITA as compared to $\mathrm{SVG}^{[10]}$. Another study done in order to determine the post-CABG prognostic factors for atherosclerosis progression that further supports the superiority of arterial grafts as the saphenous vein conduit's patency, due to it being prone to develop atherosclerosis, may act as a limiting factor for better prognosis of revascularization ${ }^{[11]}$.

This is confirmed by a prospective study aiming to find out the patency of right ITA (RITA) as compared to other conduit vessels. The study showed that, at 10 years, the patency of RITA is at least $90 \%$; RA is $70 \%$; and SVG is $50 \%{ }^{[12]}$. Thus, confirming that arterial conduits are more patent than saphenous venous conduits.

\section{Long-term clinical outcomes}

Mortality and serious adverse events are the key points when comparing TACABG with VCABG. However, no direct comparison could be made using current clinical data due to the lack of tailored studies, but TACABG and VCABG could be indirectly evaluated with the results of some trials.

According to a non-blinded prospective, randomized, open-label, non-inferiority trial published in 2016, out of 592 patients with left main disease, with mean age of 66.2 years, the 5-year Kaplan-Meier outcome estimated for all-cause mortality is 32 patients (9\%); major adverse Cardiac and Cerebrovascular Events (MACCE) occurred in 80 patients (18\%); total revascularization rate is $10 \%$, and stroke incidence was $2 \%{ }^{[13]}$. During this study, there seem to be no propensity score analysis done but the 5-year Kaplan-Meier estimates were stratified into groups based on SYNTAX score in order to reduce propensity bias. 
Another randomized trial that aims at comparing single and bilateral ITA conduits has been used to provide data for the outcome of VCABG. The data taken from this trial will be the outcome for the single ITA conduit to reduce the bias provided by using both ITA in term of sternal healing and long-term patency of graft. In this trial, there were 1554 patients with average age of 63.5 years that underwent single ITA graft plus supplementary venous or arterial conduits. The 5-year outcome found from patients follow up in term of MACCE is 198 (12.7\%), all-cause mortality was $8.4 \%$, total revascularization rate was $6.6 \%$ and stroke incidence was $3.2 \%$. As mentioned in the report, even though this trial involved statistical corrections and propensity matching, there is still chance of bias in terms of patient and operator selection. In this trial, it was mentioned that a post-hoc analysis of the SYNTAX trial compared 5-year outcomes in 456 patients who received a second arterial conduit with those in 963 patients who underwent single ITA grafting with additional vein grafts, in which propensity score adjustment was done, showing that MACCE were $23.3 \%$ in arterial group and $21.4 \%$ in venous group $(P=0.04)$. However, the all-cause mortality was $9.1 \%$ in the arterial group and $9.5 \%$ in the venous group $(P=0.19)^{[11,14]}$. From this analysis, single ITA with supplementary vein graft has better MACCE outcome as compared to total arterial revascularization. However, the starting number of arterial group is half of that venous group, showing a tighter population choice which lead to selection bias, even though propensity score has been done. On the other hand, the venous group done worse in term of all-cause mortality, although no differences were found with regards to cardiovascular mortality.

\section{Special population: patients with left main disease}

Left main CAD is the highest-risk lesion subset of ischemic heart disease and has traditionally been an indication for coronary artery bypass grafting (CABG). Significant (defined as a greater than $50 \%$ angiographic narrowing) left main disease is found in 4 to $6 \%$ of all patients who undergo coronary arteriography, and it is associated with multivessel CAD about $70 \%$ of the time. While trying to find outcome analysis available to show the result of total arterial CABG in left main disease, it has shown to be a challenge as there are not much of such data available. The closest data is that from RAPCO study ${ }^{[15]}$. In this study, radial artery was compared to either right ITA or saphenous vein and patency was then compared. The group of patients in which the result is being used here, is that of 140 patients with an average age of 60.1 years old with total arterial revascularization of their cardiac arteries. The only available results are all cause of mortality (2\%) and revascularization with PCI (2\%). RAPCO study is a prospective, randomized, single-center trial ${ }^{[15]}$. Even though the study was able to provide criteria in order to reduce selection bias due to its prospective nature, but by being a single-center trial, it may not necessarily representative of the population in general [Table 1].

A retrospective multicenter analysis comparing TACABG to VCABG, has shown that TACABG is associated with higher peri-operative as well as long-term survival ${ }^{[4]}$. In the study, the Kaplan-Meier survival within 5 years for TACABG group is $91.3 \%$ as compared to $90.1 \%$ in the VCABG patients $(P<0.01)$. Although it may seem that the survival rates are not significantly different, when compared to those of the 10 years, there seems to be a widening gap between the two groups, in which the survival for TACABG is $85.4 \%$ while VCABG is $81.2 \%(P<0.01)^{[4]}$. This study should not show a significant selection bias due to propensity score matching. Although, its nature of being a retrospective analysis may lead to some unmodifiable selection bias.

\section{DISCUSSION}

Evidence from the literature show that arterial conduits have better prognosis as compared to venous conduits when used in the revascularization of coronary arteries. However, there are certain aspects of venous conduits that are non-inferior than arterial ones.

Firstly, in term of preparation, there is a requirement to check that any of the vessels being used are intact and of satisfactory quality to provide the best outcome from undergoing CABG. While it is required to check for the patency of ulnar artery when radial artery is being used, there seem to be no requirement to 
Table 1.5-year outcome of patients in TACABG and VCABG in patients with left main disease

\begin{tabular}{|c|c|c|c|c|c|}
\hline & \multirow[b]{2}{*}{ NOBLE* } & VCABG & \multirow[b]{2}{*}{$\begin{array}{c}\text { TAR } \\
\text { Non-TAR group }\end{array}$} & \multicolumn{2}{|c|}{ TACABG } \\
\hline & & $\begin{array}{c}\text { ART } \\
\text { Single- graft group }\end{array}$ & & RAPCO $^{\star \star}$ & $\begin{array}{c}\text { TAR } \\
\text { TAR group }\end{array}$ \\
\hline Average age (years) & 66.2 & 63.5 & 64.7 & 60.1 & 64.4 \\
\hline Number of patients & 592 & 1554 & 6232 & 140 & 6232 \\
\hline MACCE & $80(18 \%)$ & $198(12.7 \%)^{\star}$ & N/A & N/A & N/A \\
\hline All-cause mortality & $32(9 \%)$ & $130(8.4 \%)$ & 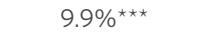 & $3(2 \%)$ & 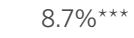 \\
\hline Cardiac death & $15(3 \%)$ & N/A & N/A & N/A & N/A \\
\hline Vascular death & $1(<1 \%)$ & N/A & N/A & N/A & N/A \\
\hline Non-procedural myocardial infarction & $10(2 \%)$ & N/A & N/A & N/A & N/A \\
\hline Revascularisation (total) & $47(10 \%)$ & $103(6.6 \%)$ & N/A & N/A & $N / A$ \\
\hline Revascularisation with $\mathrm{PCl}$ & $45(10 \%)$ & N/A & N/A & $3(2 \%)$ & N/A \\
\hline Revascularisation with CABG & $2(<1 \%)$ & N/A & N/A & N/A & N/A \\
\hline Target lesion revascularisation & $36(8 \%)$ & N/A & N/A & N/A & N/A \\
\hline Target LMCA revascularisation & $33(9 \%)$ & N/A & N/A & N/A & N/A \\
\hline $\begin{array}{l}\text { De novo lesion revascularisation } \\
\text { (new lesion in non-grafted segment) }\end{array}$ & $11(3 \%)$ & N/A & N/A & N/A & N/A \\
\hline Symptomatic graft occlusion or definite stent thrombosis & $15(4 \%)$ & N/A & N/A & N/A & N/A \\
\hline Stroke & $7(2 \%)$ & $49(3.2 \%)$ & N/A & N/A & N/A \\
\hline
\end{tabular}

${ }^{\star}$ Composite death, myocardial infarction, and stroke; ${ }^{\star \star}$ RAPCO only take RA conduit; ${ }^{* \star \star}$ Derived from Kaplan-Meier survival. CABG: coronary artery bypass graft; TACABG: total arterial CABG; VCABG: CABG that involves venous graft; PCl: percutaneous coronary intervention; LMCA: left main coronary artery; MACCE: major adverse cardiac and cerebrovascular events; TAR: total-arterial revascularization; NOBLE/ART/RAPCO refer to names of clinical trials

check for saphenous vein collateral circulation. However, it has been shown that checking for saphenous vein through the use of Doppler ultrasound improves the prognosis of $\mathrm{SVG}^{[16]}$.

Secondly, in term of operation time, the total of cross-clamp time and perfusion time is shorter in the TACABG than in VCABG (as has been discussed above), a retrospective study has shown that the operative time taken for total arterial revascularization was 30 minutes longer ${ }^{[17]}$. This is true especially when bilateral ITA or RA was used. The paper further added that the additional time taken was due to the extra conduit harvest and not to actual grafting procedure ${ }^{[17]}$.

Also, BIMA could be performed using two different configurations, in situ versus Y-graft. A recent study evaluated whether graft configuration might affect long-term outcomes in 2150 patients using a propensityscore approach ${ }^{[18]}$. Late mortality and incidence of MACCES were similar between groups, and therefore the clinical outcome of BIMA grafting is independent of surgical configuration. However, Y-grafting increases the flexibility of BIMA grafting and should be taken into account when a surgical strategy for myocardial revascularization needs to be planned ${ }^{[18]}$.

Thirdly, it is important to consider the short term post-operative outcome of a surgical procedure. An example of this is the healing of any surgical wounds inflicted during CABG procedure, especially in high risk patients (such as those with diabetes mellitus) ${ }^{[19]}$. One of the main topic of interest is the healing outcome of the sternum and chest wall after the collections of ITA, especially if bilateral ITAs were harvested. However, through careful harvesting of such grafts while preserving pleural cavities' integrity, it reduces the postoperative morbidity as well as lowering hospital $\operatorname{cost}^{[19,20]}$. One of the fear of TACABG is deep sternal wound infection (DSWI), especially if bilateral ITA was used. However, reports from various studies have shown that there were low rates of DSWI, that is lower than $1 \%$, in TACABG ${ }^{[4,21-24]}$. The incidence of DSWI may be significantly higher after the harvest of both internal thoracic arteries in the elderly, with an odds risk of 1.86 $(P<0.01)^{[25]}$. However, the risk of deep sternal wound infection can be minimized in diabetic patients undergoing CABG by performing ITA harvested in a skeletonized manner with meticulous attention to preserving sternal blood flow. Pedicled harvest is to be discouraged when utilizing both ITA owing to a significant 
increase in the risk of postoperative DSWI ${ }^{[2,2,2]}$. In fact, a recent meta-analysis showed that skeletonized ITA appears to reduce the incidence of postoperative SWI in comparison with pedicled ITA after CABG, with this effect being modulated by the presence of diabetes ${ }^{[2]}$. In the sensitivity analysis, the difference in favour of skeletonized ITA was also observed in subgroups such as diabetic, bilateral ITA and diabetic with bilateral ITA; also, there was a difference in the type of study, since non-randomized studies together demonstrated the benefit of skeletonized ITA in comparison with pedicled ITA, but the randomized studies together did not show this difference ${ }^{[2]}$. To summarize, strategies that reduce DSWI target the modifiable risk factors that include microbiological factors, appropriate antibiotic prophylaxis, tight glycemic control, while surgical strategies reduce DSWI following BIMA harvest include techniques of IMA harvesting with lesser devascularization of sternum using skeletonized, semiskeletonized and modified pedicle harvest are associated with greater preservation of sternal blood supply and sternal closure and stability techniques ${ }^{[2]}$. Antibiotic prophylaxis given to patients pre- and post-operatively helps further reduce the chance of wounds infection, improving the surgical prognosis. Diabetes acts as a risk factors for the development of atherosclerosis as it accelerates the formation of atheroma ${ }^{[30]}$. Its presence in patients who were undergoing revascularization for atherosclerosis also increased the risk of post-operative complications. A retrospective study with propensity score matching compared total arterial revascularizations to procedures that involved venous grafts in the revascularization of atherosclerosis in diabetic patients ${ }^{[17]}$. While the rate of perioperative mortality (within 30 -days post-operatively) was similar at $1.2 \%$ in total arterial CABG group as compared to $1.4 \%$ in the nontotal arterial CABG group, nonetheless the rate of late mortality (mean of 4.9 years) was less among the total arterial CABG groups at $10.2 \%$ as compared to the non-total arterial CABG group at $12.2 \%{ }^{[17]}$. Thus, adding a point towards the advantage of undergoing total arterial CABG.

Fourthly, the long-term outcome (that is mainly patient's survival rate) is also an important factor to consider before choosing a procedure. From previous discussion, it has been shown that TACABG provides a better prognosis than VCABG. However, the long-term outcome of TACABG only showed the survival rate and did not elaborate on the MACCE that would be more relevant to the finding. Then, there was also no mentioning of revascularization in this group. However, based on literature and what was known about the patency of SVG as compared to arterial grafts, it could be concluded that total arterial grafting would wield a better outcome whenever it is possible to be done. A study confirmed that by using only SVG as compared to the use of ITA, there was 1.61 times greater risk of death throughout 10 years post-operation ${ }^{[31]}$, thus further favoring arterial conduits ${ }^{[32,33]}$.

A window for development into the surgical skills that may be beneficial to patients that are undergoing CABG is by doing such procedures through off-pump method. A paper querying about The Society of Thoracic Surgeons National Cardiac Database showed that off-pump coronary artery bypass was associated with a significant reduction in risk of death, stroke, acute renal failure, mortality or morbidity, and hospital stay as compared to on-pump coronary artery bypass ${ }^{[34]}$. This does not only benefit patients (which would be one of the main points in considering on a procedure), but also help cut cost for the healthcare system (which makes the other critical point that need to be balanced together with patient's benefit and long term outcome). However, such procedures require experience as surgeons will be required to perform the surgery while the heart is still beating and thus avoiding the use of cardiopulmonary bypass pump. This would set an example in which a procedure that would be beneficial for both the patients and healthcare system requires significant investment, that is the amount of training need to be done by surgeons.

The challenge of increasing TACABG procedure lies on assuring surgeons that this procedure provides a greater benefit for patients and the healthcare system. Although there would be some exceptions for the procedure, in which VCABG can be used as an alternative when possible. In term of left main disease, there need to be more studies and results published to show the outcome (both long- and short-term) of using TACBG in the revascularization of left main disease. 


\section{CONCLUSION}

TACABG takes a longer preparation as compared to non-total arterial CABG. However, whenever it is possible to perform TACABG, the short- and long-term survival were better as compared to VCABG. In addition, the patency of arterial conduits has been shown to be longer lasting and less prone to damage as compared to venous conduits. While there was a similar 30-day outcome in both TACABG and VCABG groups, the long-term mortality rate was higher in the VCABG group as compared to TACABG. Among the arteries available to be conduits, internal thoracic arteries by far provides the best outcome, even for those with higher risk of complications.

\section{DECLARATIONS}

\section{Authors' contributions}

Manuscript conception: Dewantoro D, Spadaccio C

Literature search, writing the draft: Dewantoro D, Satriano U

Critical revision of the manuscript, writing the revised version: Nenna A, Spadaccio C

Critical revision of the manuscript: Chello $\mathrm{M}$

\section{Availability of data and materials}

Not applicable.

\section{Financial support and sponsorship}

None.

\section{Conflicts of interest}

All authors declare that there are no conflicts of interest.

\section{Ethical approval and consent to participate}

Not applicable.

\section{Consent for publication}

Not applicable.

\section{Copyright}

(c) The Author(s) 2018.

\section{REFERENCES}

1. Mackay J, Mensah GA, Greenlund K. The atlas of heart disease and stroke. World Health Organization, 2004.

2. Stone GW, Sabik JF, Serruys PW, Simonton CA, Généreux P, Puskas J, Kandzari DE, Morice MC, Lembo N, Brown WM 3rd, Taggart DP, Banning A, Merkely B, Horkay F, Boonstra PW, van Boven AJ, Ungi I, Bogáts G, Mansour S, Noiseux N, Sabaté M, Pomar J, Hickey M, Gershlick A, Buszman P, Bochenek A, Schampaert E, Pagé P, Dressler O, Kosmidou I, Mehran R, Pocock SJ, Kappetein AP; EXCEL Trial Investigators. Everolimus-eluting stents or bypass surgery for left main coronary artery disease. N Engl J Med 2016;375:2223-35.

3. Al-Sabti HA, Al Kindi A, Al-Rasadi K, Banerjee Y, Al-Hashmi K, Al-Hinai A. Saphenous vein graft vs. radial artery graft searching for the best second coronary artery bypass graft. J Saudi Heart Assoc 2013;25:247-54.

4. Tatoulis J, Wynne R, Skillington PD, Buxton BF. Total arterial revascularization: achievable and prognostically effective-a multicenter analysis. Ann Thorac Surg 2015;100:1268-75; discussion 1275.

5. Anyanwu AC, Saeed I, Bustami M, Ilsley C, Yacoub MH, Amrani M. Does routine use of the radial artery increase complexity or morbidity of coronary bypass surgery? Ann Thorac Surg 2001;71:555-9; discussion 559-60.

6. Maruthappu M, Duclos A, Lipsitz SR, Orgill D, Carty MJ. Surgical learning curves and operative efficiency: a cross-specialty observational study. BMJ Open 2015;5:e006679.

7. Gaudino M, Crea F, Cammertoni F, Mazza A, Toesca A, Massetti M. Technical issues in the use of the radial artery as a coronary artery 
bypass conduit. Ann Thorac Surg 2014;98:2247-54.

8. Samak M, Fatullayev J, Sabashnikov A, Zeriouh M, Schmack B, Ruhparwar A, Karck M, Popov AF, Dohmen PM, Weymann A. Total arterial revascularization: bypassing antiquated notions to better alternatives for coronary artery disease. Med Sci Monit Basic Res 2016; 22:107-14.

9. Gaudino M, Benedetto U, Fremes S, Biondi-Zoccai G, Sedrakyan A, Puskas JD, Angelini GD, Buxton B, Frati G, Hare DL, Hayward P, Nasso G, Moat N, Peric M, Yoo KJ, Speziale G, Girardi LN, Taggart DP; RADIAL Investigators. Radial-Artery or Saphenous-Vein Grafts in Coronary-Artery Bypass Surgery. N Engl J Med 2018;378:2069-77.

10. Goldman S, Zadina K, Moritz T, Ovitt T, Sethi G, Copeland JG, Thottapurathu L, Krasnicka B, Ellis N, Anderson RJ, Henderson W; VA Cooperative Study Group \#207/297/364. Long-term patency of saphenous vein and left internal mammary artery grafts after coronary artery bypass surgery: results from a Department of Veterans Affairs Cooperative Study. J Am Coll Cardiol 2004;44:2149-56.

11. Domanski MJ, Borkowf CB, Campeau L, Knatterud GL, White C, Hoogwerf B, Rosenberg Y, Geller NL. Prognostic factors for atherosclerosis progression in saphenous vein grafts: the postcoronary artery bypass graft (Post-CABG) trial. Post-CABG Trial Investigators. J Am Coll Cardiol 2000;36:1877-83.

12. Tatoulis J, Buxton BF, Fuller JA. The right internal thoracic artery: the forgotten conduit--5,766 patients and 991 angiograms. Ann Thorac Surg 2011;92:9-15; discussion 15-7.

13. Mäkikallio T, Holm NR, Lindsay M, Spence MS, Erglis A, Menown IB, Trovik T, Eskola M, Romppanen H, Kellerth T, Ravkilde J, Jensen LO, Kalinauskas G, Linder RB, Pentikainen M, Hervold A, Banning A, Zaman A, Cotton J, Eriksen E, Margus S, Sørensen HT, Nielsen PH, Niemelä M, Kervinen K, Lassen JF, Maeng M, Oldroyd K, Berg G, Walsh SJ, Hanratty CG, Kumsars I, Stradins P, Steigen TK, Fröbert O, Graham AN, Endresen PC, Corbascio M, Kajander O, Trivedi U, Hartikainen J, Anttila V, Hildick-Smith D, Thuesen L, Christiansen EH; NOBLE study investigators. Percutaneous coronary angioplasty versus coronary artery bypass grafting in treatment of unprotected left main stenosis (NOBLE): a prospective, randomised, open-label, non-inferiority trial. Lancet 2016;388:2743-52.

14. Parasca CA, Head SJ, Mohr FW, Mack MJ, Morice MC, Holmes DR Jr, Feldman TE, Colombo A, Dawkins KD, Serruys PW, Kappetein AP; SYNTAX Investigators. The impact of a second arterial graft on 5-year outcomes after coronary artery bypass grafting in the synergy between percutaneous coronary intervention with TAXUS and cardiac surgery trial and registry. J Thorac Cardiovasc Surg 2015; 150:597-606.e592.

15. Buxton BF, Raman JS, Ruengsakulrach P, Gordon I, Rosalion A, Bellomo R, Horrigan M, Hare DL. Radial artery patency and clinical outcomes: five-year interim results of a randomized trial. J Thorac Cardiovasc Surg 2003;125:1363-71.

16. Luckraz H, Lowe J, Pugh N, Azzu AA. Pre-operative long saphenous vein mapping predicts vein anatomy and quality leading to improved post-operative leg morbidity. Interact Cardiovasc Thorac Surg 2008;7:188-91; discussion 191.

17. Tatoulis J, Wynne R, Skillington PD, Buxton BF. Total arterial revascularization: a superior strategy for diabetic patients who require coronary surgery. Ann Thorac Surg 2016;102:1948-55.

18. Di Mauro M, Iacò AL, Allam A, Awadi MO, Osman AA, Clemente D, Calafiore AM. Bilateral internal mammary artery grafting: in situ versus Y-graft. Similar 20-year outcome. Eur J Cardiothorac Surg 2016;50:729-34.

19. Buxton BF, Hayward PA. The art of arterial revascularization-total arterial revascularization in patients with triple vessel coronary artery disease. Ann Cardiothorac Surg 2013;2:543-51.

20. Bonacchi M, Prifti E, Giunti G, Salica A, Frati G, Sani G. Respiratory dysfunction after coronary artery bypass grafting employing bilateral internal mammary arteries: the influence of intact pleura. Eur J Cardiothorac Surg 2001;19:827-33.

21. Tranbaugh RF, Dimitrova KR, Lucido DJ, Hoffman DM, Dincheva GR, Geller CM, Balaram SK, Ko W, Swistel DG. The second best arterial graft: a propensity analysis of the radial artery versus the free right internal thoracic artery to bypass the circumflex coronary artery. J Thorac Cardiovasc Surg 2014;147:133-40.

22. Parsa CJ, Shaw LK, Rankin JS, Daneshmand MA, Gaca JG, Milano CA, Glower DD, Smith PK. Twenty-five-year outcomes after multiple internal thoracic artery bypass. J Thorac Cardiovasc Surg 2013;145:970-5.

23. Puskas JD, Sadiq A, Vassiliades TA, Kilgo PD, Lattouf OM. Bilateral internal thoracic artery grafting is associated with significantly improved long-term survival, even among diabetic patients. Ann Thorac Surg 2012;94:710-5; discussion 715-6.

24. Raza S, Sabik JF, 3rd, Masabni K, Ainkaran P, Lytle BW, Blackstone EH. Surgical revascularization techniques that minimize surgical risk and maximize late survival after coronary artery bypass grafting in patients with diabetes mellitus. J Thorac Cardiovasc Surg 2014;148:1257-64; discussion 1264-56.

25. Deo SV, Altarabsheh SE, Shah IK, Cho YH, McGraw M, Sarayyepoglu B, Medalion B, Markowitz AH, Park SJ. Are two really always better than one? Results, concerns and controversies in the use of bilateral internal thoracic arteries for coronary artery bypass grafting in the elderly: a systematic review and meta-analysis. Int J Surg 2015;16:163-70.

26. Deo SV, Shah IK, Dunlay SM, Erwin PJ, Locker C, Altarabsheh SE, Boilson BA, Park SJ, Joyce LD. Bilateral internal thoracic artery harvest and deep sternal wound infection in diabetic patients. Ann Thorac Surg 2013;95:862-9.

27. Glineur D, Kuschner CE, Grau JB. Bilateral internal thoracic artery graft configuration and coronary artery bypass grafting conduits. Curr Opin Cardiol 2016;31:625-34.

28. Sá MP, Ferraz PE, Escobar RR, Vasconcelos FP, Ferraz AA, Braile DM, Lima RC. Skeletonized versus pedicled internal thoracic artery and risk of sternal wound infection after coronary bypass surgery: meta-analysis and meta-regression of 4817 patients. Interact Cardiovasc Thorac Surg 2013;16:849-57.

29. Sajja LR. Strategies to reduce deep sternal wound infection after bilateral internal mammary artery grafting. Int J Surg 2015;16:171-8.

30. Chait A, Bornfeldt KE. Diabetes and atherosclerosis: is there a role for hyperglycemia? J Lipid Res 2009;50 Suppl:S335-9.

31. Loop FD, Lytle BW, Cosgrove DM, Stewart RW, Goormastic M, Williams GW, Golding LA, Gill CC, Taylor PC, Sheldon WC. Influ- 
ence of the internal-mammary-artery graft on 10-year survival and other cardiac events. N Engl J Med 1986;314:1-6.

32. Gaudino M, Puskas JD, Di Franco A, Ohmes LB, Iannaccone M, Barbero U, Glineur D, Grau JB, Benedetto U, D’Ascenzo F, Gaita F, Girardi LN, Taggart DP. Three arterial grafts improve late survival: a meta-analysis of propensity-matched studies. Circulation 2017; 135:1036-44.

33. Glineur D, D'hoore W, Price J, Dorméus S, de Kerchove L, Dion R, Noirhomme P, El Khoury G. Survival benefit of multiple arterial grafting in a 25-year single-institutional experience: the importance of the third arterial graft. Eur J Cardiothorac Surg 2012;42:284-90; discussion 290-1.

34. Polomsky M, He X, O’Brien SM, Puskas JD. Outcomes of off-pump versus on-pump coronary artery bypass grafting: Impact of preoperative risk. J Thorac Cardiovasc Surg 2013;145:1193-8. 